\title{
El convenio relativo a la protección del niño y a la cooperación en materia de adopción internacional, hecho en La Haya el 29 mayo 1993: una aproximación heterodoxa ${ }^{1}$
}

\author{
Alfonso-Luis Calvo Caravaca \\ Catedrático de Derecho internacional privado \\ Universidad Carlos III de Madrid \\ Vocal Permanente de la Comisión General de Codificación \\ $\mathrm{y}$ \\ Javier Carrascosa González \\ Profesor Titular de Derecho internacional privado \\ Universidad de Murcia
}

Recibido: 23.10 .09

Aceptado: 16.11 .09

Resumen: El convenio relativo a la protección del niño y a la cooperación en materia de adopción internacional, hecho en La Haya el 29 mayo 1993, presenta la curiosa incidencia de no precisar la ley aplicable a ciertos aspectos necesarios para acreditar la adecuación psicosocial de los adoptantes y del adoptando. En este trabajo, se propone una interpretación fáctica que permite solventar dicho problema: las autoridades que aplican el convenio citado no deben aplicar ninguna Ley estatal concreta a los aspectos reseñados, sino que deben limitarse a acreditar la adecuación psicosocial de los adoptantes y del adoptando con arreglo a criterios fácticos, sin que sea necesario aplicar una ley estatal determinada.

Palabras clave: Adopción internacional, convenio relativo a la protección del niño y a la cooperación en materia de adopción internacional de 29 mayo 1993, ambiente psicosocial de la adopción, lagunas de Derecho internacional privado.

Abstract: The Hague Convention on the protection of the child and co-operation in respect of intercountry adoption, signed on May 29, 1993 does not specify which is the Law applicable to the psyco-social conditions of the adoptive parents and the adopted child. This paper makes a new proposal. There is no need of specyfing any applicable Law to that issue. The competent authorities should ascertaing an adequate psyco-social enviroment for the adopted child taking into account factual information and not by the application of any particular State Law.

Key words: Hague Convention on the protection of the child and co-operation in respect of intercountry adoption, applicable Law to the psyco-social conditions of the adoption.

${ }^{1}$ Versión en castellano de la contribución presentada al Convegno La famiglia senza frontiere, celebrado en la Università degli Studi di Napoli Federico II, el 16 de octubre de 2009. 
Sumario: I. Introducción.-II. El convenio relativo a la protección del niño y a la cooperación en materia de adopción internacional, hecho en La Haya el 29 mayo 1993: entre el Derecho administrativo y el Derecho internacional privado.--III. La fase administrativa previa a la adopción internacional introducida por el CH 1993.-IV. Reflexiones finales.

\section{Introducción}

1. La adopción internacional es una institución legal que goza, en Derecho internacional privado, de permanente actualidad. Ello se explica por su elevado número (= nunca como en los primeros años del siglo XXI la adopción internacional había alcanzado semejantes cifras), así como por la sensibilidad de los intereses implicados (= menores, adoptantes y Estados constituyen colectivos que reclaman regulaciones legales no siempre en el mismo sentido $)^{2}$. Dos simples ejemplos extraídos no solo de la práctica legal española pueden servir para demostrar ambos aspectos.

2. Primer ejemplo: los casos de gestación por sustitución o maternidad subrogada en California y otros Estados que permiten dichos contratos, en los que los contratantes son personas solas o personas del mismo sexo procedentes de España y otros países occidentales se han disparado (vid. por ejemplo, el famoso caso que aborda la RDGRN 18 febrero 2009 [menores nacidos en California y padres españoles]) $)^{3}$. Ello se ha producido porque, ante la escasez endémica e incesante de menores de corta edad susceptibles de ser adoptados en Occidente, los sujetos que desean adoptar acuden a los países que cuentan con menores que sí pueden ser adoptados (Camboya, China, Vietnam, Rusia, Ucrania, Colombia, etc.). Pero resulta que la legisla-

${ }^{2}$ Vid. A.-L. Calvo Caravaca / J. Carrascosa González: «Adopción internacional», en A.-L. Calvo Caravaca / J. Carrascosa González (Directores), Derecho internacional privado, vol. II, 10. a ed., Ed. Comares, Granada, 2009, pp. 253-262; TH. STEIGER: Das neue Recht der internationalen Adoption und Adoptionsvermittlung, Köln, 2002, esp. pp. 11-19; G. Pizzolante: Le adozioni nel diritto internazionale privato, Bari, Cacucci, 2008, esp. pp. 12-17; M.P. DiAGo DIAGO: «Revocable International Adoption and Spanish Law», SYIL, vol. VI, 1998, pp. 79-103; A. RoDRíGUEZ BENOT: «El reconocimiento de las medidas de protección del menor en un entorno multicultural. Un estudio comparado de la eficacia extraterritorial de la adopción y de la Kafala», $R G D$, n. ${ }^{\circ} 667,2000$, pp. 4419-4447.

${ }^{3}$ A.-L. Calvo Caravaca / J. CARRAscosa GonzÁlez: «Gestación por sustitución y Derecho Internacional Privado: Consideraciones en torno a la resolución de la Dirección General de los Registros y del Notariado de 18 de febrero de 2009», $C D T$, vol. 1, n. ${ }^{\circ}$ 2, octubre 2009, pp. 294-319; A. QuiÑONES ESCÁMEZ: «Doble filiación paterna de gemelos nacidos en el extranjero mediante maternidad subrogada», Indret, julio 2009, versión on line. En la doctrina italiana, recientemente, C. CAMPLIGLIO: «Lo stato di figlio nato da contratto internazionale di maternità», RDIPP, XLV, n. ${ }^{\circ}$ 3, 2009, pp. 589-604. 
ción de dichos países suele prohibir la adopción por parte de personas solas o de parejas del mismo sexo. Un ejemplo se puede encontrar en la denegación del permiso para adoptar emitida por el Ministerio de Familia de Ucrania en relación con el artista ELTON JOHN. El músico británico había solicitado la adopción de Lev, un niño ucraniano de 14 meses, pero las autoridades de Kiev denegaron tal adopción, entre otras causas, por la orientación homosexual de ELTON JOHN ${ }^{4}$. Conclusión: los casos «internacionales» de gestación por sustitución aumentan porque la adopción nacional y la adopción internacional por parte de personas de orientación homosexual es, en la práctica, imposible.

3. Segundo ejemplo: son frecuentes los supuestos de adopciones internacionales constituidas por autoridades no competentes, adopciones en cuya constitución se ha prescindido de las fases procesales legalmente establecidas y/o de los consentimientos o asentimientos o informaciones legalmente exigidas, casos que encubren tráfico de menores mediante consentimientos «comprados», y adopciones que no han sido realmente aprobadas por la autoridad competente, entre otros. Por desgracia, estos casos son frecuentes. En marzo de 2009 se detectó que numerosos menores procedentes del Nepal habían sido adoptados en dicho país tras haber firmado sus padres biológicos la renuncia a su patria potestad mediante engaños. Se decía a dichos padres que los menores serían entregados a un Centro Público para su mejor cuidado y los padres, con frecuencia analfabetos, firmaban la renuncia a la patria potestad creyendo que estaban firmando la entrega de los menores a tales Centros Públicos ${ }^{5}$. Los orfanatos del Nepal obtienen pingües beneficios cuando entregan en adopción a ciertos menores, algunos de los cuales tienen padres que no han consentido entregarlos para la adopción. Según UNICEF, ello reportó a tales centros, en 2006, unos dos millones de dólares USA aproximadamente. La lucha contra el tráfico de niños nunca será lo bastante severa.

\section{El convenio relativo a la protección del niño y a la cooperación en materia de adopción internacional, hecho en La Haya el 29 mayo 1993: entre el Derecho administrativo y el Derecho internacional pri- vado}

4. Hace ya dieciséis años que fue concluido el convenio relativo a la protección del niño y a la cooperación en materia de adopción internacional, hecho en La Haya el 29 mayo 1993. Tras casi quince años de vigencia en

${ }^{4}$ Diario El Mundo, 15 septiembre 2009, p. 58.

${ }^{5}$ Vid. diario El País, 3 marzo 2009 y <http://www.parasaber.com/familia/adopciones/>. 
España (entrada en vigor para España el 1 noviembre 1995) ${ }^{6}$ y casi diez años de vigencia en Italia (entrada en vigor para Italia el 1 mayo 2000) ${ }^{7}$, parece llegado un buen momento para realizar ciertas consideraciones sobre dicho convenio internacional, limitadas a la fase administrativa previa a la constitución de la adopción, y dejando al margen de este estudio los aspectos relativos a la validez extraterritorial de la adopción que se ha constituido con arreglo al procedimiento recogido en el convenio.

5. El convenio de La Haya de 29 mayo 1993, relativo a la protección del niño y a la cooperación en materia de adopción internacional (citado a partir de este momento como «CH 1993»), es un instrumento internacional de gran relieve en la regulación de las adopciones internacionales. Ha generado un notable cuerpo de práctica administrativa y judicial y, naturalmente, una inmensa cantidad de estudios específicos ${ }^{8}$. Este convenio se halla en vi-

${ }^{6}$ Texto en BOE núm. 182 de 1 agosto 1995.

${ }^{7}$ Vid. Legge 4 maggio 1983, n. 184, successivamente modificata dalla Legge 31 dicembre 1998, n. 476, che ha autorizzato il Presidente della Repubblica a ratificare la Convenzione per la tutela dei minori e la cooperazione in materia di adozione internazionale del 29 maggio 1993 (Convenzione dell' Aja).

${ }^{8}$ Vid. M. Aguilar Benítez de Lugo / B. Campuzano Díaz: «El certificado de idoneidad para las adopciones internacionales desde la perspectiva del DIPr. español», BIMJ, n. 1888, 2001, pp. 827-ss.; A. BorRÁs RodríGuEZ: «La XVIII Sesión de la Conferencia de la Haya de Derecho internacional privado, 30 septiembre 1996», REDI, 1996-II, pp. 367-363; A. BUCHER: «L'avant projet d'une convention de La Haye sur l'adoption internationale, RSDI$D E, 1993$, pp. 153-182; A. BuCHER: «Commentaire sur la Convention de La Haye du 29 mai 1993», en J. Doek, H. Van Loon y P. Vlaardingerbroek (Eds.), Children on the Move, Kluwer Law International, 1996, pp. 87-93; M. BusCH: «Adoptionswirkungsgesetz und Haager Adoptionsübereinkommen - von der Nachadoption zur Anerkennung und Wirkungsfeststellung», IPRax, 2003, pp. 13-23; W. DunCAN: «Hague Convention on the Protection of Children and Co-operation in Respect of Intercountry Adoption (29 May 1993)», International Family Law, July 1999, p. 31-34; ID.: «The Hague Children's Conventions. Some News and Developments», International Children's Rights Monitor, Vol. 13, January 2000, pp. 16-22; ID.: «The Hague Convention on the Protection of Children and Co-operation in respect of Intercountry Adoption», Adoption \& Fostering, vol. 3, 1993, pp. 9-13; ID.: «The Hague Convention on the Protection of Children and Co-operation in respect of Intercountry Adoption 1993. Some issues of special relevance to sending countries», Intercountry Adoptions: Laws and Perspectives of «Sending» Countries, Dordrecht / Boston / Londres, Martinus Nijhoff Publishers, 1995, pp. 217-227; ID.: «Intercountry Adoption: Some Issues in Implementing and Supplementing the 1993 Hague Convention on the Protection of Children and Co-operation in respect of Intercountry Adoption», en J. DoEK, H. VAN LoON / P. VlaARdingerbroek (Eds.), Children on the Move, Kluver Law International, 1996, pp. 7586; F. CALVO BABIO: «Reconocimiento en España de las adopciones constituidas en Rumanía: situaciones patológicas», La Ley, 1998-V, D-241, pp. 1585-ss.; ID.: «Nota a la RDGRN 12 julio 1996», REDI, vol. XLIX, 1997-II, pp. 272-ss.; B.L. CARRILlo CARRILLO: Adopción internacional y Convenio de La Haya de 29 mayo 1993, Granada, Ed. Comares, 2003; P. Diago Diago: «La ley francesa número 2001-111 de 16 de febrero, relativa a la adopción internacional», REDI, vol. LIII, 2001, pp. 735-739; W. DunCAN: «Conflict and Co-Opera- 
gor para multitud de países, que son tanto «países de origen» de los menores, como «países de recepción» de estos (M. Vargas Gómez-Urru-

tion. The Approach to Conflicts of Law in the 1993 Hague Convention on Intercountry Adoption», en N. Lowe/ G. Douglas, Families Across Frontiers, The Hague, 1996, pp. $577-$ 589; R. FrAnK: «The Recognition of Intercountry Adoptions in the Light of the 1993 Hague Convention on Intercountry Adoptions», en N. LowE / G. Douglass, Families Across Frontiers, The Hague, 1996, pp. 591-604; C. GonZÁlez BeILFuss: «La aplicación en España del Convenio de La Haya de 29 mayo 1993 relativo a la protección del niño y a la cooperación en materia de adopción internacional», RJC, 1996, pp. 313-345; ID.: «La entrada en vigor para España del Convenio de La Haya de 29 mayo 1993 relativo a la protección del niño y la cooperación en materia de adopción internacional», REDI, 1995 (II), vol. XLVII, pp. 485488; N. GonZÁlez MARTín: «El Convenio de La Haya de 1993 y el procedimiento de cooperación a través de una entidad colaboradora de adopción internacional: España y México», en D. AdAm MuÑoz / S. García CANo (dir.), Sustracción internacional de menores y adopción internacional, Madrid, Ed. Colex, 2004, pp. 179-212; E. GuIGOU: «Circulaire du 16 fevrèire 1999 relative à l'adoption internationale», $R C D I P$, vol. 88, 1999, pp. 600-604; M. GuZMÁn ZAPATER: «Adopción internacional: ¿Cuánto queda del Derecho Internacional Privado clásico?», en A.L. CAlvo CaravaCa y OTRos, Mundialización y familia, Madrid, Colex, 2001, pp. 83-120; M. JAMETTI-GREINER / A. BuCHER: «La Dix-septième session de la Conférence de La Haye de droit international privé», RSDIDE, 1994, pp. 55-102; M.F. LUCHER-BABEL: «Adoption Internationale: comprendre les nouvelles normes. Principes et mecanismes de la Convention de la Haye du 29 mai 1993», Les Cahiers des Droits de l'enfant, vol. 4. DEI, 1996, pp. 1-56; D.M. MARINA HERnANDO: «La intervención de las AACC españolas de comunicación en la aplicación del Convenio de La Haya de 1993 sobre adopción internacional», en D. ADAM MUÑOZ / S. GARCíA CANO (dir.), Sustracción internacional de menores y adopción internacional, Madrid, Ed. Colex 2004, pp. 161-168; M.V. MAYOR DEL HoYo: «Notas acerca del Convenio de la Haya sobre adopción internacional», RDP, 1995, pp. 1019-1043; N. MEYER-FABRE: «La Convention de La Haye du 29 mai 1993 sur la protection des enfants et la coopération en matière d'adoption internationale», RCDIP, 1994, vol. 83, pp. 259-296; H. MuIR-WATT: «La Convention de La Haye du 29 mai 93 sur la protection des enfants et la coopération en matière d'adoption internationale», TCFDIP, 1993/95, pp. 49-63; ID.: «Vers l'inadoptabilité de l'enfant étranger de statut personnel prohibitif? A propos de la circulaire du 16 février 1999 relative a l'adoption internationale», RCDIP, 1999, pp. 469-492; G. PARRA-ARANGUREN: «An Overview of the 1993 Hague InterCountry Adoption Convention», en N. Lowe/ G. Douglas (ed.), Families Across Frontiers, The Hague, 1996, pp. 565-576; ID., «Rapport explicatif», Actes et documents de la Dix-septième session, t. II, Conference de la Haye de Droit international privé, 1994, disponible en $<w w w . h c c h . n e t>$; P.H. Pfund: «Implementation of the Hague Intercountry Adoption Convention in the United States: Issues and Problems», E Pluribus Unum. Liber amicorum G.A.L. Droz. On the progressive unification of private international Law, The Hague, 1996, pp. 321-336; E. PoISSON-DrocourT: «L'entrée en vigueur de la Convention de La Haye sur la protection des enfants et la coopération en matière d'adoption internationale», JDI, 19993, pp. 707-730; A. RodRíGuez BENOT: «La eficacia en España de las adopciones simples constituidas al amparo de un ordenamiento extranjero (una relectura del art. $9.5 \mathrm{CC}$ a la luz del Convenio de La Haya de 29 mayo 1993)», en AA.VV., Estatuto personal y multiculturalidad de la familia, Madrid, Colex, 2000, pp. 181-202; C. Rudolf: «Das Haager Übereinkommen über die internationale Adoption», Zeitschrift für Rechtsvergleichung, 2001, pp. 183-198; G. STUBER: Anerkennung internationaler Adoptionen, Stuttgart, Boorberg, 2003; B. STURLĖSE: «La Convention de La Haye du 29 mai 1993 sur la protection des enfants et la 
tia) $)^{9}$. Debe tenerse presente que el CH 1993 es un convenio inter partes. Solo se aplica entre los Estados partes en él y no en relación con terceros Estados. De dicho modo, las adopciones constituidas por autoridades de Estados no partes en el CH 1993 no surten efectos jurídicos en los Estados partes en dicho convenio a través de sus normas. Igualmente, las autoridades dependientes de terceros Estados no aplican, a la hora de constituir adopciones, el citado CH 1993.

6. El CH 1993 persigue tres objetivos: $1^{\circ}$ ) establecer garantías para que las adopciones internacionales se realicen en atención al interés superior del niño y al respeto de los derechos fundamentales que les reconoce el Derecho internacional; $2^{\circ}$ ) fijar un sistema de colaboración entre las autoridades de los Estados partes para evitar el tráfico, la venta y la sustracción de los meno-

coopération en matière d'adoption internationale», JCP, I, 1993, pp. 427-433; ID.: «L'adoption des enfants étrangers: aspects relevant du droit international privé», en S. MANSOUR (Dir), L'adoption des enfants étranger, París, Centre International de l'Enfance, 1993, pp. 33-41; J.H.A. VAN LoON: «International Co-operation and Protection of Children with Regard to Intercountry Adoption», RCADI, 1993, vol. 244, pp. 191-456; ID., «Noté sur l'opportunité de preparer une nouvelle convention sur une coopération internationale en matière d'adoption inter-etatique», Actes el documents de la Sexième session, t. I, Hague Conférence on Private International Law, 1991, pp. 164-185; ID.: «Rapport sur l'adoption d'enfants originaires de l'etranger. Document préliminaire 1 d'avril 1990», Actes et documents de la Dix-septième session, Tome II, Conference de La Haye de droit international privé, 1994, pp. 10-119; ID.: «Intercountry adoption of children: a challange for international cooperation to protext children's rights», Hague Yearbook of International Law, 1992, pp. 137147; ID.: «The Increasing Significance of International Co-operation for the Unification of Private International Law», Forty Years On: The Evolution of Postwar Private International Law in Europe, Kluver, Deventer, 1990, pp. 101-122; D. WINKELSTRÄTER: Anerkennung und Durchführung internationaler Adoptionen in Deutschland: unter Berücksichtigung des Haager Übereinkommens über den Schutz von Kindern und die Zusammenarbeit auf dem Gebiet der internationalen Adoption vom 29. Mai 1993, Jena, 2007.

${ }^{9}$ El convenio se halla en vigor en los siguientes Estados (septiembre 2009): Albania, Alemania, Andorra, Antigua República Yugoslava de Macedonia, Armenia, Austria, Azerbayán, Bielorrusia, Bélgica, Belice, Bolivia, Brasil, Bulgaria, Burkina Faso, Burundi, Camboya, Canadá, Colombia, Costa Rica, Chile, Chipre, Dinamarca, Ecuador, El Salvador, Eslovaquia, Eslovenia, España, Estados Unidos de América (desde el 1 de abril de 2008), Estonia, Filipinas, Finlandia, Francia, Georgia, Gran Bretaña e Isla de Man, Guatemala, Guinea, Hungría, India, Islandia, Israel, Italia, Kenia, Letonia, Liechtenstein, Lituania, Luxemburgo, Madagascar, Mali, Malta, Mauricio, México, Moldova, Mónaco, Mongolia, Noruega, Nueva Zelanda, Países Bajos, Panamá, Paraguay, Perú, Polonia, Portugal, Rumania, República Checa, República Dominicana, República Popular China, San Marino, Seychelles, Sri Lanka, Sudáfrica, Suecia, Suiza, Tailandia, Turquía, Uruguay y Venezuela. Más datos sobre las Declaraciones de los Estados en relación con este convenio, así como sobre la entrada en vigor para cada Estado y sobre los nuevos Estados partes, pueden encontrarse en la web oficial de la Conferencia de La Haya de Derecho internacional privado (<http://www. hcch.net/>). 
res; $\left.3 .^{\circ}\right)$ potenciar de manera muy relevante el reconocimiento de pleno derecho, en los Estados partes, de las adopciones realizadas con arreglo a lo dispuesto en el CH 1993.

7. Ahora bien, para comprender cómo el CH 1993 trata de lograr dichos objetivos y para que dicho convenio deje de ser considerado un «objeto jurídico no identificado», resulta importante percibir que dicho instrumento legal constituye, en general, un convenio de Derecho administrativo internacional. En efecto, el CH 1993 regula las relaciones, competencias y funciones de las autoridades administrativas de los Estados partes que intervienen en la constitución de adopciones internacionales. Solo en lo que se refiere a los efectos jurídicos que surten en los Estados partes las adopciones constituidas según dicho CH 1993 en otros Estados partes puede considerarse que el Convenio opera en el ámbito del Derecho internacional privado (DIPr.).

8. Para lograr sus objetivos, el $\mathrm{CH} 1993$ apunta en varias direcciones.

1. $\left.{ }^{\circ}\right)$ Profundiza en la publificación de las adopciones. El CH $1993 \mathrm{crea}$ una «fase administrativa» previa a la constitución de la adopción internacional entre los Estados partes en el convenio. Esta fase aparece construida sobre la cooperación de autoridades de diversos Estados y supone un control exhaustivo de la adopción por parte de autoridades públicas. Su objetivo es evitar el «tráfico de niños» que trata con frecuencia de encubrirse con una adopción internacional «legalizante».

$\left.2^{\circ} .^{\circ}\right)$ Persigue alcanzar un auténtico «efecto útil». El convenio fomenta su ratificación por el mayor número posible de países, y procura que tales países sean tanto «países de origen» de los menores, como «países de recepción» de estos, lo que aumenta el «efecto útil» del convenio.

3. ) Amplía su radio material de acción. Visto que existen diferentes «modelos de adopción» en los países del mundo, el CH 1993 se declara aplicable a toda adopción, ya sea una adopción «simple», «menos plena» $\mathrm{o}$ «plena», revocable o irrevocable.

4. $\left.{ }^{\circ}\right)$ Acoge el sistema del «reconocimiento de pleno derecho» de las adopciones constituidas con arreglo al convenio. El CH 1993 busca evitar las «adopciones claudicantes» (= adopciones válidas en un país, pero consideradas «no existentes» y/o «no válidas» en otros). El convenio trata de alcanzar dicho objetivo mediante una «cláusula de reconocimiento de pleno derecho» (art. $23 \mathrm{CH} 1993$ ). Dicha cláusula obliga a los países signatarios del CH 1993 a aceptar como «existentes y válidas» las adopciones constituidas en otro Estado parte con arreglo al CH 1993, sin necesidad de exequatur, ni de reconocimiento por homologación ni de cualquier otro procedimiento. 


\section{La fase administrativa previa a la adopción internacional introduci- da por el CH 1993}

9. El CH 1993 introduce, como se ha indicado, una nueva «fase administrativa» en la constitución de la adopción internacional. Dicha fase comprende una serie de controles administrativos que deben realizar las autoridades de los Estados partes, controles relacionados de modo sucinto en el Capítulo II del convenio. En el seno de dicha fase administrativa cabe distinguir dos aspectos.

En primer lugar, las autoridades del Estado parte de origen del niño deben asegurar la oportunidad de entregar a este en adopción (internacional) (vid. art. 4 CH 1993) ${ }^{10}$. En efecto, las autoridades administrativas del Estado de origen deben corroborar que una adopción internacional resulta la medida de protección más adecuada en relación con el menor del que se trate. A tal efecto, dichas autoridades deben acreditar que el niño es adoptable y que ha sido convenientemente informado del proceso de adopción y de las consecuencias que ello comporta, que una adopción internacional responde al interés superior del niño porque no resulta más beneficiosa para este que una adopción que suponga la colocación del niño en el Estado de origen de este,

10 Art. 4 CH 1993: «Las adopciones consideradas por el Convenio solo pueden tener lugar cuando las Autoridades competentes del Estado de origen:

a) Han establecido que el niño es adoptable;

b) Han constatado, después de haber examinado adecuadamente las posibilidades de colocación del niño en su Estado de origen, que una adopción internacional responde al interés superior del niño;

c) Se han asegurado de que:

1. Las personas, instituciones y autoridades cuyo consentimiento se requiera para la adopción han sido convenientemente asesoradas y debidamente informadas de las consecuencias de su consentimiento, en particular con relación al mantenimiento o ruptura, en virtud de la adopción, de los vínculos jurídicos entre el niño y su familia de origen.

2. Han dado su consentimiento libremente, en la forma legalmente prevista y que este consentimiento ha sido dado o constatado por escrito.

3. Los consentimientos no se han obtenido mediante pago o compensación de clase alguna y que tales consentimientos no han sido revocados.

4. El consentimiento de la madre, cuando sea exigido, se ha dado únicamente después del nacimiento del niño.

d) Se han asegurado, teniendo en cuenta la edad y el grado de madurez del niño, de que:

1. Ha sido convenientemente asesorado y debidamente informado sobre las consecuencias de la adopción y de su consentimiento a la adopción, cuando este sea necesario.

2. Se han tomado en consideración los deseos y opiniones del niño.

3. El consentimiento del niño a la adopción, cuando sea necesario, ha sido dado libremente en la forma legalmente prevista y que este consentimiento ha sido dado o constatado por escrito.

4. El consentimiento no ha sido obtenido mediante pago o compensación de clase algu$n a »$. 
que la familia biológica del menor y/o demás personas o instituciones a cargo del niño han dado su libre consentimiento para la adopción internacional, y que todos los consentimientos requeridos no se han obtenido mediante pago de precio u otras compensaciones.

En segundo lugar, las autoridades del «Estado de recepción» del niño deben realizar una serie de controles administrativos para acreditar que el entorno familiar de destino del menor es el adecuado. En efecto, tales autoridades deben corroborar que los futuros padres adoptivos son «adecuados y aptos para adoptar», que han sido convenientemente asesorados, y que el niño ha sido o será autorizado a entrar y residir permanentemente en el Estado de recepción (vid. art. 5 CH 1993) ${ }^{11}$.

10. Este sistema de «reparto distributivo de competencias administrativas» entre las autoridades de los Estados partes funciona del siguiente modo: 1..$\left.^{\circ}\right)$ las autoridades del Estado de recepción elaboran un informe sobre los adoptantes y lo transmiten a la Autoridad Central del Estado de origen (art. $15 \mathrm{CH} 1993)^{12} ; 2^{\circ}$ ) las autoridades del Estado de origen elaboran otro informe sobre el adoptando (art. $16 \mathrm{CH} 1993)^{13}$ y lo remiten a la Autoridad

${ }^{11}$ Art. 5 CH 1993: «Las adopciones consideradas por el Convenio solo pueden tener lugar cuando las Autoridades competentes del Estado de recepción:

a) Han constatado que los futuros padres adoptivos son adecuados y aptos para adoptar.

b) Se han asegurado de que los futuros padres adoptivos han sido convenientemente asesorados.

c) Han constatado que el niño ha sido o será autorizado a entrar y residir permanentemente en dicho Estado».

${ }^{12}$ Art. 15. 1 CH 1993: «Si la Autoridad Central del Estado de recepción considera que los solicitantes son adecuados y aptos para adoptar, preparará un informe que contenga información sobre su identidad, capacidad jurídica y aptitud para adoptar, su situación personal, familiar y médica, su medio social, los motivos que les animan, su aptitud para asumir una adopción internacional y sobre los niños que estarían en condiciones de tomar a su cargo. 2. Esta Autoridad Central transmitirá el informe a la Autoridad Central del Estado de origen».

${ }^{13}$ Art. 16 CH 1993: «1. Si la Autoridad Central del Estado de origen considera que el niño es adoptable:

a) Preparará un informe, que contenga información sobre la identidad del niño, su adoptabilidad, su medio social, su evolución personal y familiar, su historia médica y la de su familia, así como sobre sus necesidades particulares.

b) Se asegurará de que se han tenido debidamente en cuenta las condiciones de educación del niño así como su origen étnico, religioso y cultural.

c) Se asegurará de que se han obtenido los consentimientos previstos en el artículo 4.

d) Constatará si, basándose especialmente en los informes relativos al niño y a los futuros padres adoptivos, la colocación prevista obedece al interés superior del niño.

2. Esta Autoridad Central transmitirá a la Autoridad Central del Estado de recepción su informe sobre el niño, la prueba de que se han obtenido los consentimientos requeridos y la motivación de la decisión relativa a la colocación, procurando no revelar la identidad de la madre y el padre, si en el Estado de origen no puede divulgarse su identidad». 
Central del Estado de recepción, junto con una «propuesta concreta de colocación del niño» y la prueba de que se han obtenido los consentimientos requeridos (art. 16.2 $\mathrm{CH} 1993$ ); $3 .^{\circ}$ ) debe producirse un «acuerdo» entre las Autoridades Centrales de ambos Estados (= conocido como The Matching Process), en cuya virtud ambas autoridades consientan en que el proceso de adopción debe continuar (art. $17 \mathrm{CH} 1993$ ); 4..$^{\circ}$ ) si existe acuerdo, las autoridades del Estado de origen confían el niño a los padres adoptivos, y se permite su salida del Estado de origen (art. 19 CH 1993); 5.) la adopción del niño puede tener lugar en el Estado de origen o en el Estado de recepción, pero esta cuestión ya no se regula por el CH 1993.

11. Pues bien, la tesis, sin duda heterodoxa, que se mantiene en el presente estudio, puede formularse de manera sencilla en la siguiente proposición: las autoridades de los Estados partes que intervienen en la fase administrativa de la adopción internacional creada por el CH 1993 deben elaborar informes que acrediten la conveniencia de dicha adopción desde un punto de vista psicológico, social, médico, personal, sociológico y ético, y desde la doble perspectiva del Estado de origen (= adecuación psicosocial del niño para ser adoptado) y del Estado de recepción (= adecuación psicosocial de los solicitantes para ser padres adoptivos). En general, dichas autoridades competentes no pueden practicar, porque no es su función, un control «legal» sobre la futura adopción internacional. Es decir, tales autoridades no valoran, en ningún momento, la «legalidad» de la futura adopción. El control legal de la adopción escapa a sus funciones y el CH 1993 no regula dicha cuestión. Las autoridades que operan en virtud de los arts. 4 y $15 \mathrm{CH} 1993$, por un lado, y 5 y $16 \mathrm{CH} 1993$, por otra parte, solo realizan un control de carácter psicológico, médico, personal, sociológico y ético, y no realizan ningún control «legal» de la adopción. En conclusión, el CH 1993 introduce una fase administrativa previa a la adopción internacional, fase que reviste un perfil social, psicológico y ético (= pues consiste en un control de las «condiciones psicosociales de la adopción», frase que aparece repetidamente en el Informe Oficial del CH 1993, ad ex. en núm. marginal 308), pero no se controlan aspectos «legales» de la adopción internacional. Esta tesis constituye un potente Flucht nach vorne, un «audaz movimiento hacia adelante» y, por ello, no está exenta de riesgos. La tesis suscita, naturalmente, diversas reflexiones.

12. En primer lugar, esta tesis permite explicar por qué el CH 1993 no precisa qué ley estatal deben aplicar las autoridades competentes en virtud de los arts. 4, 5, 15 y $16 \mathrm{CH}$ para acreditar los extremos que aconsejan entregar en adopción a un concreto niño a unos padres adoptivos específicos. En efecto, el CH 1993 no concreta esta cuestión porque los extremos que deben acreditar tales autoridades de los Estados de origen y de recepción constituyen meras «cuestiones de hecho» (= por ejemplo, la situación social de la 
familia receptora, el perfil psicológico del niño, la situación económica de los adoptantes, sus cualidades sociales, psicológicas, éticas y morales, y otras cuestiones de este tipo). Por lo tanto, tales extremos se acreditan mediante meros «exámenes fácticos» de la situación que no requieren la aplicación de ninguna Ley estatal concreta. Además, resulta extraordinariamente llamativo que un convenio elaborado por la Conferencia de La Haya de DIPr. guarde silencio en relación con dichos extremos. Estaríamos en presencia de una presunta laguna legal de Derecho internacional privado en un convenio elaborado por una organización especializada en el Derecho internacional privado. Pues bien, no hay ninguna laguna legal y no la hay porque, en general, las autoridades de los Estados partes no necesitan aplicar ninguna ley estatal para cumplir con las funciones de carácter no jurídico que les asigna el convenio.

13. En segundo lugar, esta tesis puede defenderse a pesar del tenor del art. 15.1 CH 1993. En efecto, los arts. 4 y 5, así como el 16 CH 1993, señalan que las autoridades competentes deben acreditar una serie de extremos de tipo social, familiar, psicológico, ético, económico, familiar, pero en ningún momento se precisa que tales autoridades deban comprobar extremos de carácter jurídico (= capacidad legal, edad legal, impedimentos legales para la adopción, sujetos que deben dar su consentimiento o asentimiento a la adopción y modo en el que tales declaraciones de voluntad deben prestarse, etc.). Ahora bien, el art. 15.1 CH 1993 parece suscitar un difícil inconveniente para la tesis aquí defendida, porque el texto del precepto afirma que «[s]i la Autoridad Central del Estado de recepción considera que los solicitantes son adecuados y aptos para adoptar, preparará un informe que contenga información sobre su identidad, capacidad jurídica y aptitud para adoptar...». Es decir, el precepto se refiere a extremos de carácter claramente jurídico (= la «capacidad jurídica y aptitud para adoptar» de los solicitantes de adopción). Sin embargo, la redacción del art. 15.1 CH 1993 constituye un inconveniente más aparente que real. En efecto, un examen del texto legal en el texto auténtico del CH 1993 en lengua inglesa permite despejar las nubes que surgen en el horizonte, ya que su wording excluye toda referencia a términos estrictos como es la «capacidad jurídica». Así pues, el art. $15.1 \mathrm{CH}$ 1993 en lengua inglesa indica que « $i i] f$ the Central Authority of the receiving State is satisfied that the applicants are eligible and suited to adopt, it shall prepare a report including information about their identity, eligibility and suitability to adopt, background, family and medical history, social environment, reasons for adoption, ability to undertake an intercountry adoption, as well as the characteristics of the children for whom they would be qualified to care». El término eligibility no debe ser traducido como «capacidad legal», diga lo que diga el texto oficial en lengua castellana publicado en el BOE, sino como «requisitos» o «idoneidad». Aunque el texto, también auténtico, del CH 1993 en lengua francesa, vuelve a sembrar dudas sobre la 
cuestión, ya que se refiere expresamente a «leur capacité légale et leur aptitude à adopter», la tesis aquí sostenida permite explicar de modo más satisfactorio la, en principio, llamativa inexistencia en el texto del CH 1993 de una norma de conflicto que señale la ley aplicable a los extremos que deben acreditar las autoridades de los Estados partes que participan en la adopción internacional.

14. En tercer lugar, esta tesis permite proporcionar, además, una más adecuada explicación del sentido y alcance de esta fase administrativa previa a la adopción internacional. El Convenio carece de normas que regulan la competencia judicial internacional ${ }^{14}$ y la ley aplicable a la adopción internacional ${ }^{15}$. Por ello, resulta conveniente recordar que la fase administrativa previa a la adopción internacional es una fase que «se suma» a la necesaria constitución de la adopción por la autoridad competente al efecto y a la necesaria precisión de la ley aplicable. El convenio no regula ninguna de estas dos cuestiones: ni la «competencia judicial internacional» para constituir, modificar, revisar, modificar o declarar la nulidad de una adopción internacional, ni tampoco regula la «ley aplicable» a la adopción internacional. Así las cosas, el convenio solamente exige la superación de una fase administrativa previa a la adopción internacional en la que las autoridades de los Estados partes únicamente deben verificar «aspectos psicosociales» y no aspectos «estrictamente legales» (= la verificación de los requisitos legales necesarios para la constitución de la adopción es una «cuestión excluida del $\mathrm{CH}$ 1993»). Las expresiones contenidas en el Informe Oficial del CH 1993, que parecen indicar que las autoridades competentes para instruir la fase administrativa regulada por el convenio deben acreditar no solo los aspectos psicosociales de la adopción internacional sino también, en ocasiones, ciertos «requisitos legales» necesarios para la constitución de la adopción, no deben llamar a confusión. En efecto, el informe referido indica, con frecuencia, que el CH 1993 busca garantizar la elaboración de informes que acrediten, exclusivamente, las «condiciones psicosociales» tanto de los niños como de los padres adoptivos, sin entrar en aspectos relativos a los «requisitos legales» de la adopción ${ }^{16}$. En esta perspectiva, cabe recordar que aunque el informe

${ }^{14}$ R. BARATTA: «La giurisdizione italiana in materia di adozione di minori», RDI, 1988, vol. LXXI, pp. 48-85; A. BEGHE LORETI: L'adozione dei minori nelle legislazioni europee, Milán, 1986; A. BonOMI: «La disciplina dell'adozione internazionale dopo la riforma del diritto internazionale privato», Rivista di diritto civile, 1996, pp. 355-372.

${ }^{15}$ F. PIETRANGELI: «Richiamo internazionalprivatistico e applicazione del diritto del foro nella constituzione delle adozione di minori secondo la legge di riforma», RDIPP, 1997-3, pp. 557-590; L. PINESCHI: «L'adozione da parte di persona singola: obblighi internazionali e profili internazionalprivatistici», RDIPP, 1995, pp. 313-340.

${ }^{16}$ Vid. G. PARRA-ARANGUREN: «Rapport explicatif», Actes et documents de la Dix-septième session, t. II, Conference de la Haye de Droit international privé, 1994, disponible en $<w w w . h c c h . n e t>$, núm. 308 («psychological conditions [of the child]») y núm. 117. 
explicativo del CH 1993 señala en su número marginal 180 que «the competent authorities of the receiving State have to determine that the prospective adoptive parents comply with two different kinds of requirements: (a) to be "eligible", i.e. to fulfil all legal conditions; and (b) to be "suited", meaning to satisfy the necessary socio-psychological qualification», y ello parecería invitar a pensar que las autoridades del Estado de recepción deben acreditar la capacidad jurídica de los futuros padres adoptantes, esta percepción debe matizarse para no incurrir en una conclusión errónea por precipitada. Y ello por varias razones.

Primera: porque tanto el convenio como su informe explicativo son perfectamente conciliables si se entiende que la autoridad del Estado de recepción debe limitarse a una «consideración general» sobre la capacidad de los adoptantes (= una mera aproximación sobre el sí/no de la capacidad legal de los adoptantes, un mero «juicio básico» sobre dicha capacidad). Dicho «juicio básico sobre la capacidad» tiene como objetivo descartar los supuestos más evidentes de incapacidad para evitar seguir adelante con un expediente relativo a una adopción que resultaría legalmente inviable. Así, por ejemplo, las autoridades que aplican el CH 1993 podrían descartar la emisión de informe favorable sobre los adoptantes en los supuestos en los que el solicitante sea una persona incapacitada judicial o legalmente, o una persona jurídica, y también se evitaría, por ejemplo, que se emitiera un informe favorable a la adopción de un sujeto que es evidentemente mayor de edad. De ese modo, la autoridad que ejerce funciones administrativas en virtud del CH 1993 no suplanta en sus funciones a la autoridad que debe proceder a la constitución de la adopción (= que es la que realmente ostenta la función de constituir la adopción: en España, los jueces y tribunales, no las autoridades administrativas competentes para la aplicación en España del CH 1993).

Segundo: porque esta interpretación conciliadora resuelve el problema que se plantearía si tales autoridades tuvieran que acreditar plenamente la capacidad jurídica de adoptantes y en su caso, del adoptado. En efecto, si ello fuera así, resultaría que la capacidad para adoptar debería ser corroborada dos veces: en primer lugar, por la autoridad competente en virtud del CH 1993 (= normalmente, una autoridad administrativa) y en segundo lugar, por la autoridad competente para la constitución de la adopción (= normalmente, una autoridad judicial), lo que resultaría cuanto menos llamativo y con frecuencia, inútil y absurdo.

Tercero: porque las autoridades competentes para la aplicación del CH 1993 no son las competentes, ex convenio, para constituir la adopción. En consecuencia, deben limitarse a una mera «apreciación general» de la capacidad de adoptantes y adoptando, ya que tales normas están diseñadas para ser «aplicadas» por las autoridades que, realmente, son competentes para constituir la adopción. 
15. En cuarto lugar, esta tesis permite afirmar que, visto que el CH 1993 no regula ni la competencia judicial internacional ni la ley aplicable a la adopción internacional, en el caso de que las autoridades competentes en virtud de convenio deban acreditar la «capacidad jurídica básica» de los adoptantes y del adoptado, tales autoridades no deben aplicar ninguna concreta norma de competencia judicial internacional y ninguna concreta norma de conflicto. La precisión de la norma de DIPr. aplicable, en efecto, no es necesaria. Ello permite explicar de manera adecuada el silencio que mantiene el Informe Explicativo del Convenio en relación con las normas de conflicto que deberían, teóricamente, resultar aplicables a estos extremos. En efecto: la acreditación de la capacidad jurídica de adoptantes y adoptando que realizan las autoridades competentes según el CH 1993 no es más que una «aproximación básica» que, en modo alguno, vincula a la autoridad competente para constituir la adopción internacional. La autoridad que constituye la adopción internacional decidirá de modo independiente y con plena libertad sobre la capacidad jurídica de tales sujetos. De hecho, puede suceder que, superada la fase administrativa recogida en el $\mathrm{CH}$ 1993, la autoridad (= normalmente, una autoridad judicial) competente para la constitución de la adopción, decida no proceder a ella por falta de capacidad de los adoptantes o adoptando, o por cualquier otra causa recogida legalmente. Por otra parte, la adopción puede constituirse en el país de recepción del niño, con lo que puede suceder que la ley reguladora de la capacidad de este para ser adoptado se rija, en dicho país, por una norma de conflicto distinta y por una ley material diferente a la que aplicará la autoridad que realmente constituye la adopción en el Estado de recepción del niño. Y viceversa: la adopción puede constituirse en el Estado de origen del menor, con lo que la ley reguladora de la adopción será la fijada por la norma de conflicto de dicho Estado, que bien puede ser diferente de la norma de conflicto y de la ley material que aplicó la autoridad del Estado de recepción del niño a la hora de valorar la capacidad legal de los adoptantes. Por ello, puede afirmarse que las referencias de los arts. 4, 5, 15 y 16 CH 1993 a la capacidad jurídica para adoptar de los adoptantes y a la adoptabilidad del niño no son más que «aproximaciones generales» cuyo sentido es permitir que la autoridad que aplica el CH 1993 acredite que, en general, los padres adoptivos y el menor no parecen incurrir en incapacidades legales para la adopción (= aproximación básica sobre la capacidad legal para adoptar y ser adoptado), sin que sea preciso que la autoridad que aplica el CH 1993 realice un control legal estricto, con arreglo a la Ley designada por sus normas de conflicto, de la capacidad legal de niño y potenciales padres adoptivos. Finalmente, cabe recordar que las autoridades competentes en virtud de los arts. 4, 515 y 16 CH 1993 suelen ser autoridades administrativas, carentes de la formación jurídica y de las funciones legales propias de los jueces y tribunales, razón que aconseja limitar su intervención a la acreditación de la conveniencia psicosocial de la adopción sin permitir que se pronuncien sobre la legalidad de constitución de la adopción. 
16. En quinto lugar, y visto que el $\mathrm{CH} 1993$ no regula ni la competencia judicial internacional ni la ley aplicable a la adopción internacional, debe dejarse claro que el convenio no ha unificado dichos criterios en los Estados partes. Cada Estado parte sigue, por tanto, criterios distintos para acreditar la competencia de sus autoridades para constituir adopciones y criterios diferentes para señalar la ley aplicable a la adopción internacional. En esta perspectiva, el convenio no ha unificado nada de nada y en nada ha contribuido a la seguridad jurídica «internacional». El Forum Shopping sigue siendo posible en materia de adopción internacional y los particulares implicados deben estudiar, «país por país», los diferentes sistemas de Derecho internacional privado estatales antes de iniciar los trámites de adopción internacional.

\section{Reflexiones finales}

17. No cabe duda de que el convenio relativo a la protección del niño y a la cooperación en materia de adopción internacional, hecho en La Haya el 29 mayo 1993, ha contribuido a un incremento notable de la lucha contra las prácticas fraudulentas y siniestras de tráfico de niños y de compraventa de menores encubiertas tras un maquillaje de adopción internacional. Desde este punto de vista, su mera existencia debe ser objeto de inmediata aprobación y juicio positivo. Sin embargo, el peculiar carácter de este instrumento legal ha suscitado dudas y controversias en la doctrina especializada y en la práctica judicial y administrativa. Aspectos que deben ser colocados aufs Tapet para una mejor comprensión del convenio en cuestión.

En primer lugar, ciertos autores han entendido que dicho convenio supone, al menos en España, una «desjudicialización» de la adopción, lo que no es cierto. El convenio ha supuesto un incremento del carácter administrativo de la adopción porque ha introducido una fase administrativa necesaria e imprescindible en la adopción internacional. Sin embargo, el convenio no pretende sustraer competencias a los jueces en relación con la constitución de la adopción para entregárselas en bandeja a las autoridades administrativas que aplican el convenio. El enfoque que se propone en este trabajo, aun a riesgo de convertirse en vox clamantis in deserto, permite asumir una visión más pragmática del $\mathrm{CH}$ 1993, que debe pasar a ser contemplado como un convenio que otorga competencias administrativas de carácter psicosocial a las autoridades encargadas de aplicarlo y que no se pronuncia sobre los extremos jurídicos relativos a la legalidad de la adopción, que están excluidos del convenio. Al regular competencias de carácter administrativo de las autoridades competentes, este convenio se halla más cerca del Derecho administrativo internacional que del Derecho internacional privado, dejados aparte los aspectos concernientes al reconocimiento de adopciones certificadas con arreglo al CH 1993, que son aspectos que, tras trazar la opor- 
tuna «línea alejandrina» que los separa de las cuestiones de carácter administrativo, deben abordarse, indudablemente, con las técnicas propias del Derecho internacional privado.

En segundo lugar, el convenio es criticable porque, al añadir una fase administrativa en la adopción internacional, ello no evita la necesaria aplicación de las normas de competencia judicial internacional y de las normas de conflicto de los Estados partes, y el convenio, pudiendo haberlo hecho, no ha unificado tales normas probablemente porque era un objetivo demasiado ambicioso. Esta «estrategia del avestruz» no evita, naturalmente, que al no regular estos aspectos propios del Derecho internacional privado, estos desaparezcan. El resultado es inevitable: Forum Shopping, inseguridad jurídica internacional, criterios distintos de país a país... En suma, otro caso más de Mystifikation legal, tan frecuentes, por desgracia, en Derecho internacional privado.

En tercer lugar, el CH 1993 no se ha pronunciado sobre algunos extremos relevantes en la práctica jurídica actual. En particular, el CH 1993 se aplica cualquiera que sea el adoptante: cónyuges de diferente o mismo sexo, persona sola soltera o no y parejas de hecho del mismo o diferente sexo. Pero esa perspectiva no resuelve nada, porque deja la cuestión en manos del Derecho internacional privado de cada Estado parte. En consecuencia, en los Estados partes cuyas legislaciones prohíben la adopción por parte de personas de orientación homosexual, Estados que disponen de un elevado número de niños adoptables, resulta que las personas de orientación homosexual no pueden adoptar. En la práctica, ello conduce a que tales sujetos no puedan convertirse en padres adoptivos y se recurra a la gestación por sustitución «internacional».

La interpretación audaz del CH 1993 que se propone en este estudio permite comprender mejor el auténtico carácter del Convenio y permite también una aplicación incontaminada de este, que se circunscribe al ámbito puramente administrativo. Y sirve, además, de humilde homenaje a la siempre revolucionaria máxima de Gabriele D'Annunzio: «memento audere semper» (recuerda atreverte siempre). 